\title{
Investigation of different C-backings for targets
}

Annett Hübner, Birgit Kindler, Bettina Lommel, Jutta Steiner, Vera Yakusheva, J. Khuyagbaatar, David J. Hinde, and Mahananda Dasgupta

Citation: AIP Conference Proceedings 1962, 030001 (2018); doi: 10.1063/1.5035518

View online: https://doi.org/10.1063/1.5035518

View Table of Contents: http://aip.scitation.org/toc/apc/1962/1

Published by the American Institute of Physics

\section{Articles you may be interested in}

Actinide targets for fundamental research in nuclear physics

AIP Conference Proceedings 1962, 030009 (2018); 10.1063/1.5035526

Preparation of multilayer graphene sheets and their applications for particle accelerators

AIP Conference Proceedings 1962, 030005 (2018); 10.1063/1.5035522

Preparation of osmium targets with carbon backing

AIP Conference Proceedings 1962, 030002 (2018); 10.1063/1.5035519

Preface: The 28th International Conference of the International Nuclear Target Development Society (INTDS2016)

AIP Conference Proceedings 1962, 010001 (2018); 10.1063/1.5035511

ANITA (Advanced Network for Isotope and TArget laboratories) - The urgent need for a European target preparation network

AIP Conference Proceedings 1962, 020001 (2018); 10.1063/1.5035514

UCx target preparations and characterizations

AIP Conference Proceedings 1962, 020003 (2018); 10.1063/1.5035516

A P Conference Proceedings

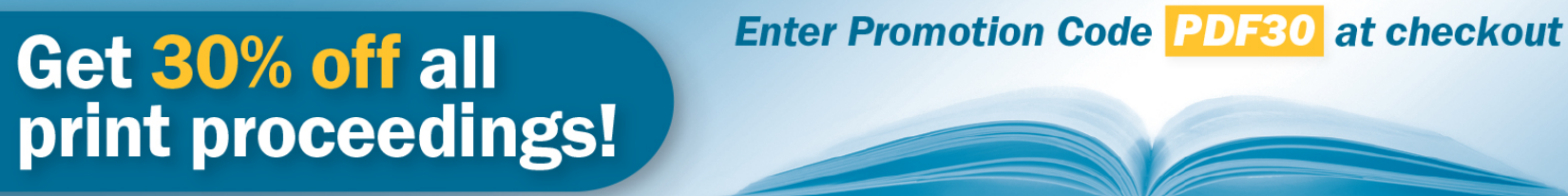




\title{
Investigation of different C-backings for targets
}

\author{
Annett Hübner ${ }^{1, \mathrm{~b})}$, Birgit Kindler ${ }^{1, \mathrm{a})}$, Bettina Lommel ${ }^{1, \mathrm{c})}$, Jutta Steiner ${ }^{1, \mathrm{~d})}$, Vera \\ Yakusheva $^{1, \mathrm{e})}$, J. Khuyagbaatar ${ }^{1,2, \mathrm{f})}$, David J. Hinde ${ }^{3, \mathrm{~g})}$ and Mahananda Dasgupta ${ }^{3, \mathrm{~h})}$ \\ ${ }^{I}$ GSI Helmholtztentrum für Schwerionenforschung, Planckstrasse 1, Darmstadt 64291, Germany \\ ${ }^{2}$ Helmholtz Institute Mainz, 55099 Mainz, Germany \\ ${ }^{3}$ Research School of Physics and Engineering, Australian National University, Canberra, ACT 2601, Australia \\ ${ }^{\text {a) Corresponding author: b.kindler@gsi.de }}$ \\ b) a.huebner@gsi.de \\ c)b.lommel@gsi.de \\ d) j.steiner@gsi.de \\ f)j.khuyagbaatar@gsi.de \\ g) david.hinde@anu.edu.au \\ h)Mahananda.Dasgupta@anu.edu.au
}

\begin{abstract}
For a special application, carbon-backings with a very flat surface, microscopically as well as macroscopically, were needed as backings for targets of enriched isotopes. However, betaine-sucrose routinely applied at GSI as parting agent for carbon deposition results in a microscopically rough surface which was not perfectly satisfying the experimental requirements. For these targets we investigated the carbon-backing quality in relation to the applied different parting agents and different deposition processes. In this paper we report on the yield, on the structure of the carbon layers and the deposited target layer of ${ }^{208} \mathrm{PbS},{ }^{206} \mathrm{PbS}$, and ${ }^{142} \mathrm{NdF}_{3}$ depending on the parting agent, the thickness and the deposition methods. We report on elastic scattering experiments with a ${ }^{48}$ Ti-beam demonstrating the influence of the structure of the carbon backing on the experimental results.
\end{abstract}

\section{INTRODUCTION}

The target production is one of the main issues of heavy ion induced physics. Various kinds of targets with different sizes and materials are required to be produced depending on the particular experiment. Often those materials are isotopically enriched and cannot be produced as self-supporting targets, depending on the thickness.

The GSI accelerator can deliver a heavy ion beam with intensity of up to tens of $\mu \mathrm{A}$ and therefore is suited to perform experiments dealing with the synthesis of heavy or super-heavy nuclei in the fusion-evaporation reactions. These experiments imply targets with relatively large areas $\left(\right.$ several $\left.\mathrm{cm}^{2}\right)$ and thickness up to few milligrams per $\mathrm{cm}^{2}$ area.

Therefore targets have to survive a high intensity beam without significant damage for as long as possible. For such experiments targets with a carbon backing prepared on betaine-sucrose proved to be most suitable since the somewhat wavy foil can better withstand deformational stress upon irradiation thus enhancing the durability of the targets significantly, as described by Lommel et al. [1].

Recently the GSI super-heavy chemistry group has initiated collaboration with the Australian National University (ANU) in Canberra and in 2013 various isotopically enriched targets with a thickness of about $150 \mu \mathrm{g} / \mathrm{cm}^{2}$ on a carbon backing were needed for their experiments. These experiments were dedicated to study the nuclear reactions 
by measuring the fission-like fragments. Targets were produced at GSI with a standard carbon backing prepared with betaine-sucrose as parting agent and delivered to ANU for the experiments where were irradiated with a ${ }^{48} \mathrm{Ti}$-beam.

The ${ }^{48}$ Ti-beam was delivered by the 14 UD Tandem accelerator of ANU and the beam intensity was about few nA. During the experiment the elastically scattered beam was continuously monitored by small area ion-implanted $\mathrm{Si}$ detectors, measuring in transmission at forward angles. A corresponding typical spectrum for a ${ }^{208} \mathrm{PbS}$ target is shown in Fig. 1(a). Compared both to expectation and to spectra measured from a self-supporting Au target, significantly broader elastic scattering energy distributions were measured with a noticeable tail towards lower energies. As a consequence, these targets were not perfectly suited to the experiments which aimed to investigate a fine structure of the mass distributions of fission fragments originating from the fusion-fission and/or quasi-fission reactions [2]. Therefore an investigation of these targets was initiated in order to improve their surface structure and thickness homogeneity. Here we report on the investigations of targets produced with different carbon backings and the development of a process leading to targets more suitable for the dedicated experiments where the homogeneity of the target thickness microscopically as well as macroscopically is necessary.

\section{INVESTIGATION OF CARBON BACKINGS}

The surface structure of the carbon backing was analyzed with a scanning electron microscope. In Fig. 1(b) a carbon backing produced by deposition on betaine-sucrose as interlayer is shown. A distinct topology resulting from the crystalline structure of the applied betaine-sucrose parting agent is clearly visible. It was assumed that this structure of the carbon backing could be a reason for the observed shape of the elastic peak (see Fig. 1(a)). Since deposited material is replicating the carbon backing structure, the resulting targets would also be structured in the similar way.

For the experiments dedicated to the fission fragment mass measurements, like those at ANU, homogenous targets i.e. carbon backings with microscopically and macroscopically flat surfaces are preferable. They have to be durable enough to survive a coating with about $150 \mu \mathrm{g} / \mathrm{cm}^{2}$ of ${ }^{208} \mathrm{PbS}$ as target material, for example, as well as the transport from Germany to Australia. Therefore a process was developed for obtaining flat carbon target backings on which the target material could be deposited homogeneously over the relevant target area of about $15 \mathrm{~mm} \times 25 \mathrm{~mm}$, keeping in mind the costs for the isotopically enriched target material.
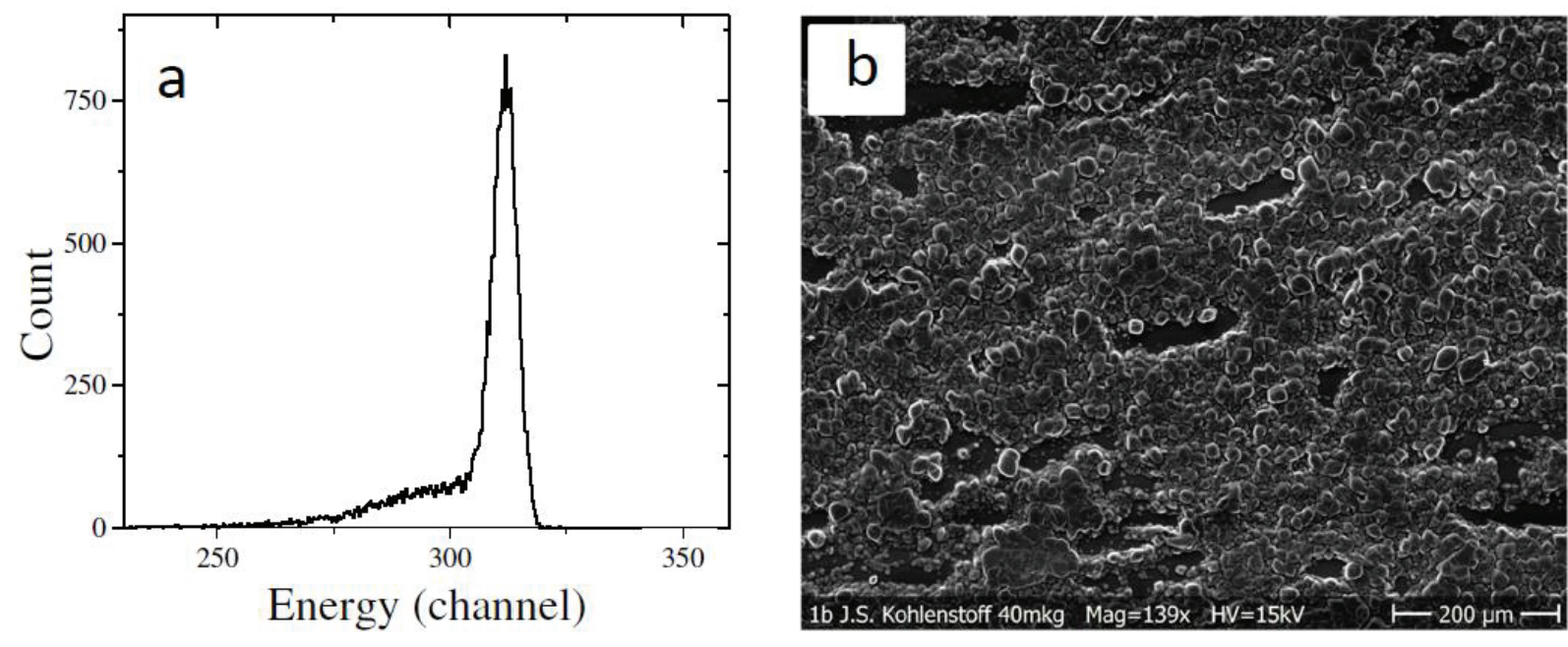

FIGURE 1. Properties of ${ }^{208} \mathrm{PbS}$-target with carbon backing produced on a glass with an interlayer of betaine-sucrose. a) Elastically scattered ${ }^{48}$ Ti-beam energy measured by a small area Si-detector. b) Picture of target surface from a scanning electron microscope. 


\section{PROCESS DEVELOPMENT}

\section{Parting Agent}

The applied parting agent has a crucial influence on the structure of the deposited foil, as already investigated in 1972 by Braski [3]. We tested three different parting agents that are customary, beside the betaine sucrose, in our laboratory: two tensides, ${ }^{\circledR}$ Pril and ${ }^{\circledR} \mathrm{Creme}$ Cote, and an alkali halide, potassium chloride $(\mathrm{KCl})$. The tensides were rubbed on the glass sheets with a lint-free cloth. The $\mathrm{KCl}$ was thermally evaporated on the glass plates with a large source-to-substrate distance of about $20 \mathrm{~cm}$ to ensure a homogeneous thickness distribution across the quite large area.

The carbon layers with thickness of about $30 \mu \mathrm{g} / \mathrm{cm}^{2}$ on both of the tensides were already visibly stressed on the glass plate, as shown in Fig. 2(a), and broke or dispersed upon floating in water. This failure might be due to the fact that the parting agent on the glass plate gets quite hot because of the direct radiation of the carbon rod during deposition. In contrary, first tests with carbon layers prepared on a $\mathrm{KCl}$ interlayer resulted in homogeneous and stress-free layers, as depicted in Fig. 2(b). Carbon foils deposited on $\mathrm{KCl}$ could easily be floated and picked on frames having a smooth and shiny surface. Therefore $\mathrm{KCl}$ was chosen as parting agent for C-backing preparation and in further steps we optimized the parameters of the subsequent process i.e. deposition of the target material on the backing.
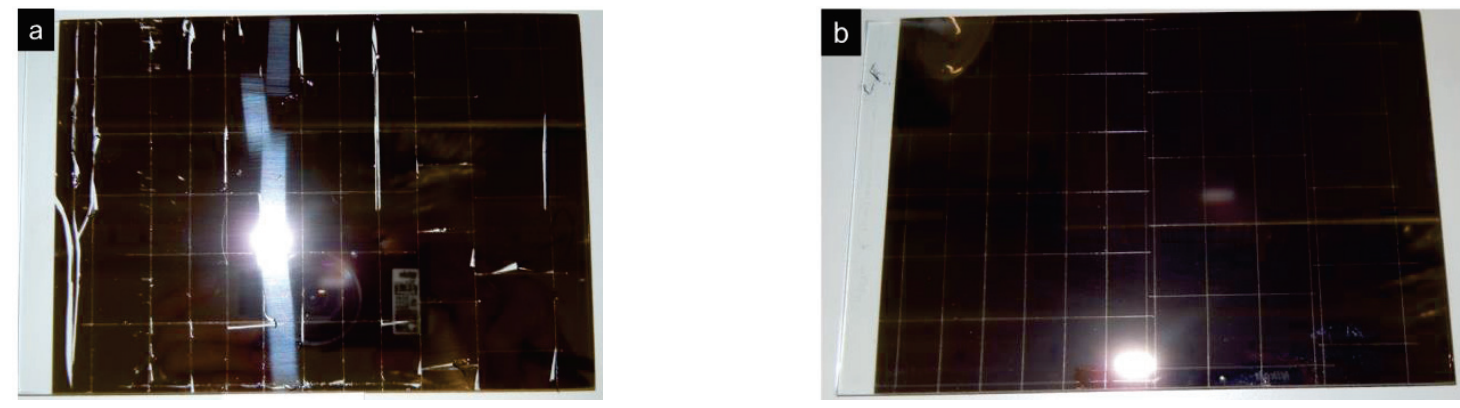

FIGURE 2. Carbon layer on glass with an interlayer (a) of a tenside; (b) on potassium chloride.

\section{Optimization of Process Parameters for the Target Production}

At first, an appropriate combination of the thickness of the parting agent and of the carbon layer had to be found in an iterative process. To determine the dependence of the thickness of the interlayer on the floating process and the quality of the carbon backings, glass plates were coated with $\mathrm{KCl}$ with a thickness of about $50 \mathrm{~nm}, 75 \mathrm{~nm}, 100 \mathrm{~nm}$ and $150 \mathrm{~nm}$, respectively; several samples were prepared for each thickness. The thickness was monitored and reproduced by means of a quartz crystal monitor to have a relative measure, the absolute thickness of the parting agent layer being of no importance.

The carbon backings were produced in a dedicated machine by direct heating of a spectroscopically pure graphite rod. Eight glass plates with dimensions $100 \mathrm{~mm} \times 150 \mathrm{~mm}$ as substrates can be coated in one run with a high reproducibility and a high similarity of thickness distribution for all plates. The properties of the resulting carbon backings for two different thickness ranges were investigated. For a systematic test, two of the KCl-coated glass plates of each thickness were mounted in the holder for each deposition run and carbon was deposited with a thickness of 20 to $25 \mu \mathrm{g} / \mathrm{cm}^{2}$ and, in a second run with "new" $\mathrm{KCl}$-coated plates, with a thickness of 35 to 40 $\mu \mathrm{g} / \mathrm{cm}^{2}$.

In second step, after dismounting the plates from the chamber the carbon layer was scribed on the glass to rectangles according to the dimensions of the frames, floated off in deionized water and mounted on the frames. The frames with the carbon backings were then mounted on a deposition wheel in another coating apparatus in which the 
isotopically enriched target material was evaporated on the backings in a very close geometry (distance source substrate $\sim 25 \mathrm{~mm}$ ) during rotation of the evaporation wheel, as described in detail in [4].

The quality of the subsequent layers or foils, respectively, were monitored in each step of the process, the results are compiled in Table 1. In the case of thinner carbon layers in the range of 20 to $25 \mu \mathrm{g} / \mathrm{cm}^{2}$ thickness all foils broke either already in the floating process already or during the deposition of the target material. The thicker foils were more stable and the survival rate increased with increasing thickness of the parting agent, somewhat saturating at $100 \mathrm{~nm}$. Thicker layers of the parting agent were of no advantage and only prolonged the preparation time.

As a result of the investigations we chose $100 \mathrm{~nm}$ as appropriate thickness for the $\mathrm{KCl}$-interlayer and 35 to 40 $\mu \mathrm{g} / \mathrm{cm}^{2}$ as suitable thickness for the carbon backing.

TABLE 1. Monitoring of the mechanical stability of the carbon backings and the yield of ${ }^{208} \mathrm{PbS}$-targets in dependence of the thickness of the parting agent and of the thickness of the carbon backing.

\begin{tabular}{|c|c|c|c|}
\hline \multicolumn{2}{|c|}{ KCl-layer (thermal evaporation) } & \multicolumn{2}{|c|}{$\begin{array}{l}\text { Carbon layer (resistance heating) } \\
\text { Coating with } 150 \mu \mathrm{g} / \mathbf{c m}^{2}{ }^{208} \mathrm{PbS} \text { (thermal evaporation) }\end{array}$} \\
\hline Thickness & Deposition Time & $20-25 \mu \mathrm{g} / \mathrm{cm}^{2}$ & $35-40 \mu \mathrm{g} / \mathrm{cm}^{2}$ \\
\hline $50 \mathrm{~nm}$ & $\sim 1.5 \mathrm{~min}$ & Carbon foils break during floating & $\begin{array}{l}\text { Carbon foils can be floated and mounted on frames } \\
\text { about } 50 \% \text { yield at coating with PbS }\end{array}$ \\
\hline $75 \mathrm{~nm}$ & $\sim 2 \min$ & Carbon foils break during floating & $\begin{array}{c}\text { Carbon foils can be floated and mounted on frames } \\
\text { about } 75 \% \text { yield at coating with PbS }\end{array}$ \\
\hline $100 \mathrm{~nm}$ & $\sim 3$ min & $\begin{array}{c}\text { Carbon foils can be floated and mounted on } \\
\text { frames } \\
\text { Break upon coating with PbS }\end{array}$ & $\begin{array}{c}\text { Carbon foils can be floated and mounted on frames } \\
\quad>\mathbf{9 0 \%} \text { yield at coating with } \mathrm{PbS}\end{array}$ \\
\hline $150 \mathrm{~nm}$ & $\sim 5 \min$ & $\begin{array}{c}\text { Carbon foils can be floated and mounted on } \\
\text { frames } \\
\text { Break upon coating with PbS }\end{array}$ & $\begin{array}{l}\text { Carbon foils can be floated and mounted on frames } \\
>\mathbf{9 0 \%} \text { yield at coating with } \mathbf{P b S} \text {. }\end{array}$ \\
\hline
\end{tabular}

\section{Comparison of Backings Quality}

The carbon backings prepared with $\mathrm{KCl}$ as parting agent with the optimized process parameters found with our investigation were much smoother than the ones prepared on betaine-sucrose, as can be seen already with the naked eye and in the photos in Fig. 3(a) and (b), respectively. The picture of the surface of a carbon backing prepared on $\mathrm{KCl}$ as parting agent taken with a scanning electron microscope (SEM) presented in Fig. 3(c) shows this improvement unequivocally. At this magnification no surface inhomogeneities were visible contrary to the surface of the carbon foil prepared on betaine as parting agent (see Fig. 1b).

\section{Mounting Carbon Backing}

Since the suitable parameters for the preparation of the targets, like the kind of interlayer and the appropriate thickness of interlayer and of carbon backing, were found, one problem remained: mounting the carbon backings targets before the deposition of the target material flat on the special frame with size of $19.2 \mathrm{~mm}$ x $9.6 \mathrm{~mm}$ (half-size ANU frame) which were later used at ANU. Though the carbon foils could be lifted very flat and smooth on a frame from the water they slackened upon drying. Attempts to stretch the foils on the frame during drying or to stretch them after drying failed, leading to a rupture of the foil. Therefore we developed a process for preparing the carbon 
backing for deposition of the target material. The floated carbon foils were fetched on larger frames and then were remounted to the required half-size ANU frames subsequent to the drying.
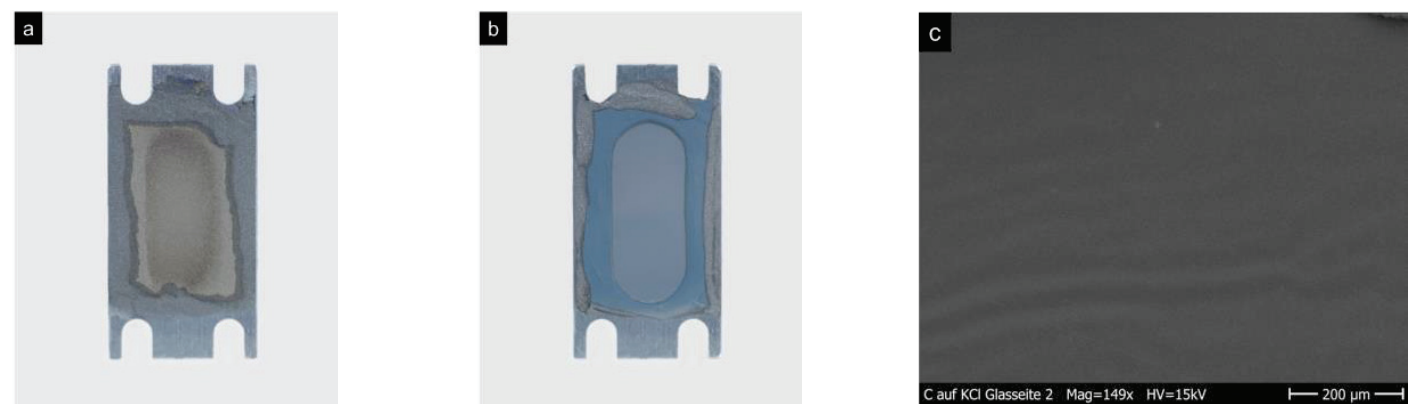

FIGURE 3. Carbon backing (a) prepared on betaine-sucrose as parting agent; (b) prepared on $\mathrm{KCl}$ as parting agent; (c) SEM image of carbon backing prepared on $\mathrm{KCl}$.

In Fig. 4 the process we developed by trial and error is demonstrated. At first, the carbon backings are lifted from the water on a GSI standard frame with aperture of $20 \mathrm{~mm}$ in diameter which is significantly larger than the aperture in the half-size ANU frame. After the carbon foils had dried we remounted them on the half-size ANU frames while tensioning the foils slightly with a ring. The so-mounted carbon backings were then coated with the isotopically enriched target material, as already described in section 3.2.

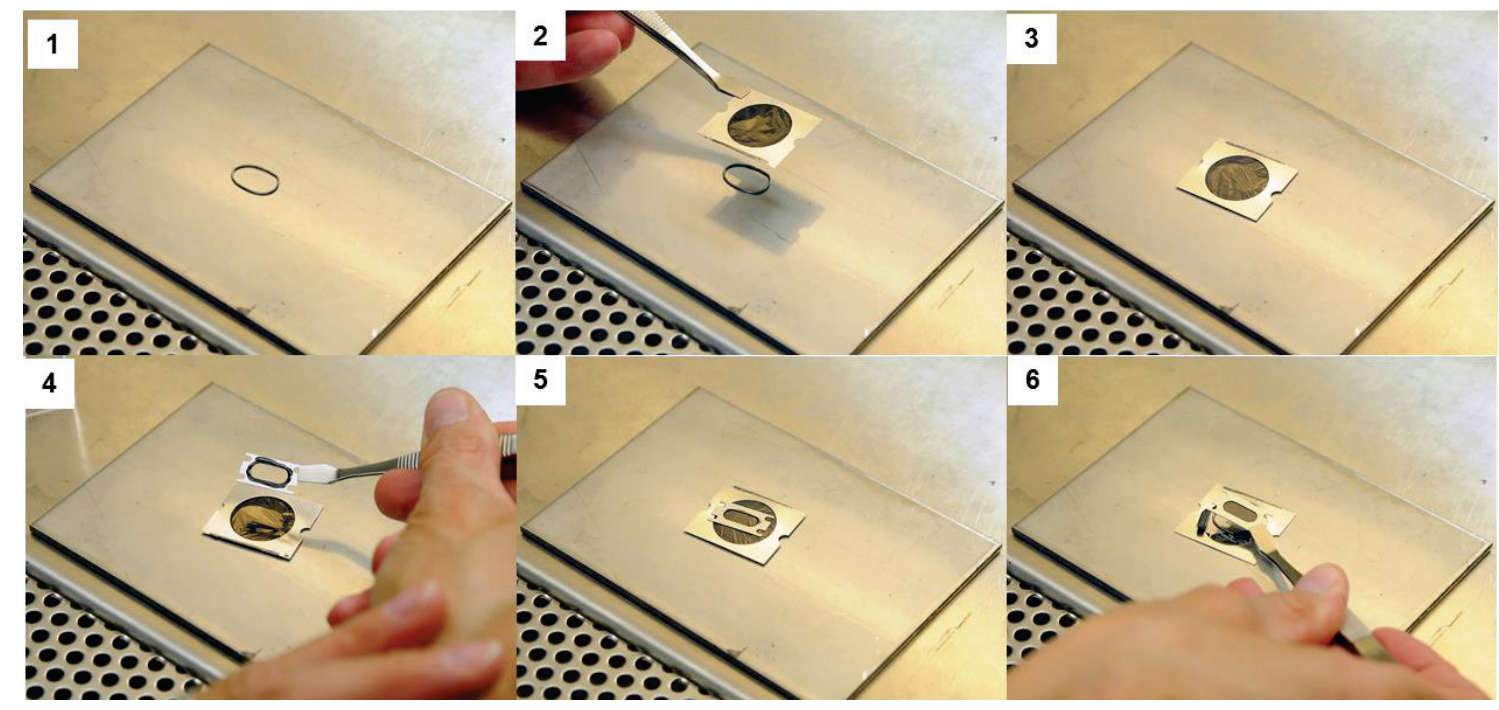

FIGURE 4. Process of remounting the carbon backing flat on the ANU frame.

With this remounting process we had a yield of about $30 \%$ backings that resulted in targets flat enough to be suitable for the experiments at ANU. We hope to improve this efficiency in the future but since we had only a limited time for target delivery and also the absolute number of targets needed was not too high, we adopted this process for the moment to be able to prepare the isotopically enriched ${ }^{208} \mathrm{PbS}$ and ${ }^{206} \mathrm{PbS}$-targets, as well as ${ }^{142} \mathrm{NdF}_{3^{-}}$ targets to meet the schedule of the planned beam time. 


\section{RESULTS OF TARGET TESTING}

Targets with ${ }^{208} \mathrm{PbS},{ }^{206} \mathrm{PbS}$ and with ${ }^{142} \mathrm{NdF}_{3}$ were prepared on carbon backings produced on betaine-sucrose as parting agent and as well with carbon backings prepared according to the above described process and sent to Canberra, Australia. In November 2016 they were tested with a ${ }^{48} \mathrm{Ti}$-beam, again comparing the measured shape of the elastic peak.

The results of these tests are shown in Fig. 5 for four different targets. Panels on the left show the results for the targets prepared on the carbon backings produced on betaine-sucrose applied as parting agent, the panels on the right show the results for the targets prepared on the carbon backings produced on $\mathrm{KCl}$ as parting agent. Relative widths of the elastic peaks $\Delta \mathrm{E} / \mathrm{E}$ were extracted as a full width at half maximum over the peak position and results are given for each target. As a first result, the low energy tail is absent in all spectra of the targets made on the carbon backing produced with $\mathrm{KCl}$ as parting agent while for all those with betaine-sucrose as parting agent the tailing is present, though differently pronounced. This demonstrates the significant improvement of the target surface flatness when prepared on carbon backing produced on $\mathrm{KCl}$ parting agent; also the energy resolution of the elastic peaks is superior compared to that for targets prepared with betaine-sucrose.

Moreover, it seems that the tail in the energy distribution for targets prepared on betaine-sucrose as parting agent became more pronounced with increasing amount of target material, as is obvious when comparing the peaks on the left panel in Fig. 5, namely Fig. 5(e) with $120 \mu \mathrm{g} / \mathrm{cm}^{2}$, Fig. 5(a) and (c) with $180 \mu \mathrm{g} / \mathrm{cm}^{2}$ and Fig. 5(g) with 223 $\mu \mathrm{g} / \mathrm{cm}^{2}$ target thickness, respectively.

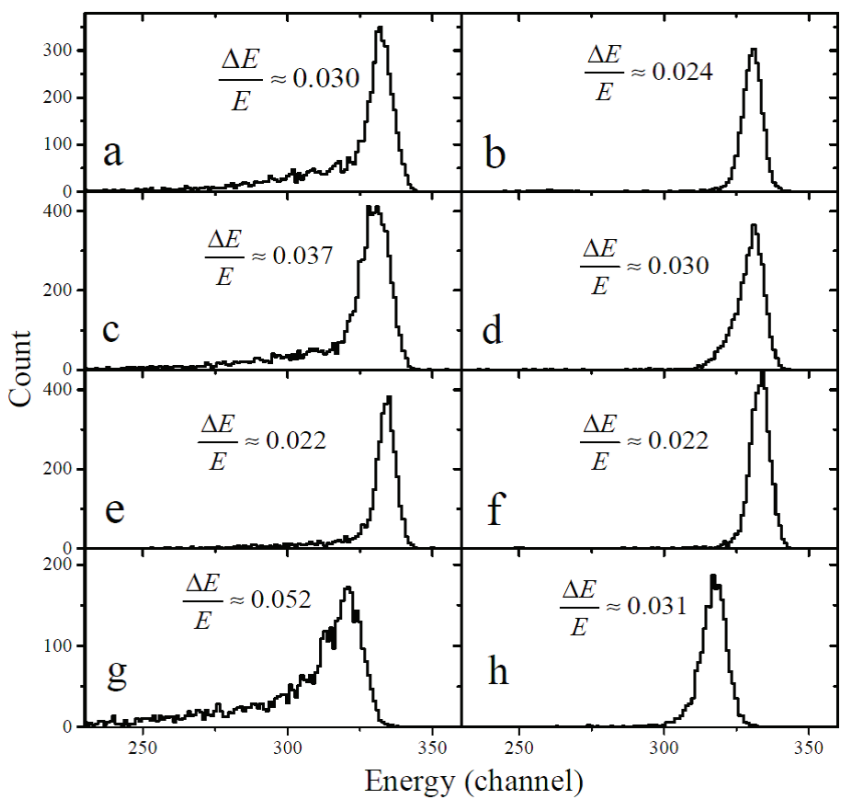

FIGURE 5. Comparison of the energy distribution for an elastically scattered ${ }^{48} \mathrm{Ti}$ beam on different targets on carbon backing prepared (left panels) on betaine-sucrose and (right panels) on $\mathrm{KCl}$ as parting agent, (a), (b) ${ }^{208} \mathrm{PbS}$ targets with thicknesses of about $180 \mu \mathrm{g} / \mathrm{cm}^{2}$; (c), (d) ${ }^{206} \mathrm{PbS}$ targets with thicknesses of about $180 \mu \mathrm{g} / \mathrm{cm}^{2}$; (e), (f) ${ }^{206} \mathrm{PbS}$ targets with thicknesses of about $120 \mu \mathrm{g} / \mathrm{cm}^{2}$. (g), (h) ${ }^{142} \mathrm{NdF}_{3}$ targets with thicknesses of about $223 \mu \mathrm{g} / \mathrm{cm}^{2}$. Relative widths ( $\Delta \mathrm{E}$, full widths at half maximum) of each peak are given.

\section{SUMMARY AND OUTLOOK}

The influence of the parting agents on the quality of the produced carbon backing and thus on the quality of the target was investigated in order to find out the most suitable way of preparing the targets dedicated to the 
experiments where good surface flatness and thickness homogeneity are required. Carbon backings produced on betaine-sucrose and $\mathrm{KCl}$, respectively, show significant differences in the surface structure observed with a scanning electron microscope, the latter showing a flat surface with no structure deformations visible.

We developed a practicable process for the preparation of carbon backings with potassium chloride as parting agent, and a way for remounting the carbon backings on another frame to ensure a flat and smooth surface of the resulting targets. The so-prepared targets were irradiated with a heavy ion beam and the measured elastic peaks confirmed the advantages of the targets produced with use of potassium chloride. A possible influence of the betaine-sucrose and $\mathrm{KCl}$ parting agents on the widths of the mass distribution of the fission fragments from the nuclear reactions will be discussed elsewhere in [5].

For similar target preparation in the near future the mounting process could be improved by construction of a gadget to allow for a slow and controlled lowering and lifting of the target frame and thus enhancing the yield substantially.

\section{ACKNOWLEDGMENTS}

We are indebted to staff of the ANU Heavy Ion Accelerator Facility for providing a stable beam. The authors

thank Dr. Alexander Yakushev of the SHE chemistry group of GSI for fruitful discussions and Gabi Otto for the photos.

\section{REFERENCES}

1. B. Lommel, W. Hartmann, B. Kindler, J. Klemm, J. Steiner, Nucl. Instr. and Meth. A 480, 199-203 (2002).

2. J. Khuyagbaatar et al., Phys. Rev. C 91, 054608 (2015).

3. D. N. Braski, Nucl. Instr. and Meth. 102, 553 (1972).

4. B. Kindler, D. Ackermann, W. Hartmann, F.P. Heßberger, S. Hofmann, B. Lommel, R. Mann, J. Steiner, Nucl. Instr. and Meth. A 561, 107-111 (2006).

5. J. Khuyagbaatar, to be published. 